\title{
PORTABLE INSTRUMENTS AND TiPS ON Practical Gemology IN THE FIELD
}

By Edward W. Boehm

Buying gems or jewelry can be challenging even when one has access to a fully equipped lab. However, most purchases are actually made in environments that make it difficult to carry anything more than a loupe, a flashlight, and a pair of tweezers. Practice with these and the additional portable gem instruments described in this article will enable the buyer to develop the keen senses needed to better ascertain the identity and quality of the material being considered. Practical tips that may be applied in the field are also included in each section. Common sense must dictate how a clue is applied, and some tests will merely help narrow down the possibilities.

T he use of practical gemological techniques is essential when purchasing gems at the source, in a dealer's office, or at trade shows. Applying common sense and a few simple tests often reveals the true nature of the gem being considered, thereby providing the buyer with important knowledge for negotiating a purchase (see Matlins and Bonanno, 1997). The instruments required to perform these gemological tests in the field must be portable and easy to use (figure 1). Advances in desktop gemological instruments over the past two decades have greatly influenced the evolution of portable instrumentation (Liddicoat, 1981, 1982). Smaller circuits and batteries, as well as more durable lightweight materials, have allowed for the development of more practical and compact instruments to keep pace with today's well-traveled gemologists.

There are several steps that should be taken to determine the properties of a polished gem or piece of rough. These steps should progress in the following order: observing transparency, color, and luster, as well as searching for obvious surface clues that might reveal fracture, cleavage, or hardness; louping the stone for internal characteristics; using a dichroscope to determine the material's general optic character; and gathering the information provided by a handheld spectroscope, polariscope, ultraviolet lamp, refractometer, and the like, to further narrow down the possibilities. It is important not to reach a conclusion too quickly and to perform further tests if there is any doubt. By careful process of elimination, in most cases a knowledgeable gemologist can determine the correct identity of a gem material. Even avoiding an unconfirmed identity by creating a reasonable doubt can prevent a bad purchase. In addition to using the proper portable instruments, it is essential to maintain current and in-depth knowledge of gemological properties and treatments. Practicing with gems most often sought on buying trips will enhance the identification skills necessary to make quick and informed decisions.

The present article looks at each of these steps as they are commonly performed in the field, and briefly describes field uses for both traditional and relatively new portable gemological instruments. Note that while brand names are mentioned in a number of instances (because these are instruments the author has used), often there may be similar instruments available from other manufacturers.

\footnotetext{
See end of article for About the Author and Acknowledgments.

GeMS \& GeMOlogr, Vol. 37, No. 4, pp. 14-27

(C) 2002 Gemological Institute of America
} 

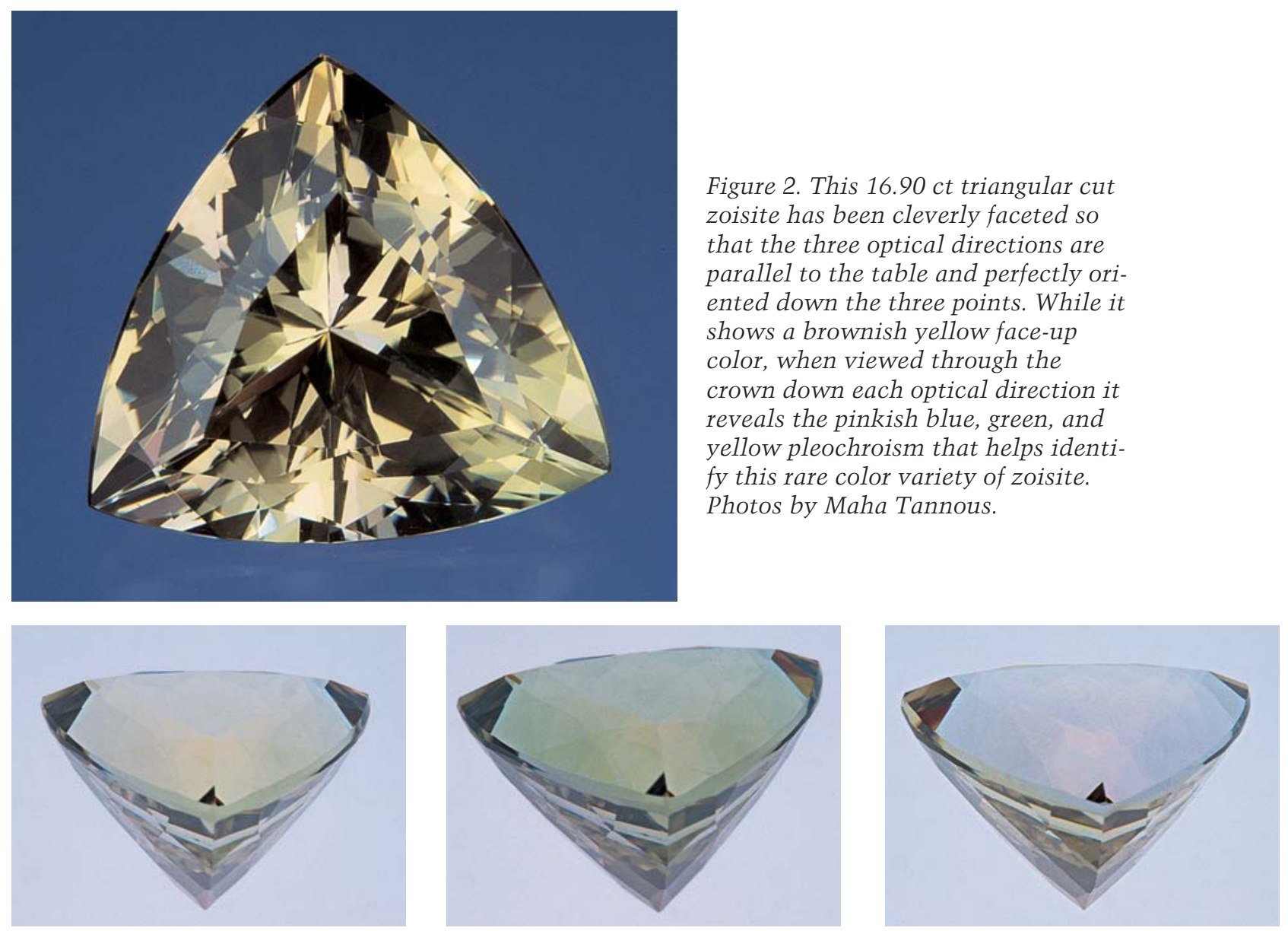

Figure 2. This $16.90 \mathrm{ct}$ triangular cut zoisite has been cleverly faceted so that the three optical directions are parallel to the table and perfectly orishows a brownish yellow face-up color, when viewed through the crown down each optical direction it reveals the pinkish blue, green, and yellow pleochroism that helps identify this rare color variety of zoisite. Photos by Maha Tannous. ented down the three points. While it given the privilege of viewing. An astute gemologist does not even have to travel far to uncover a rare treasure. Gemologists have been known to find chameleon diamonds in estate mountings because the seller had not bothered to check or had no knowledge of color-change diamonds.

When examining a piece of rough, it is important

Figure 3. This chrysoberyl preform shows a silky area (left) that may produce a cat's-eye effect on polishing. A drop of safflower oil (center) reveals the potential cat's-eye, which proved to be very sharp in the polished $13.68 \mathrm{ct}$ stone (right). Photos by Maha Tannous.
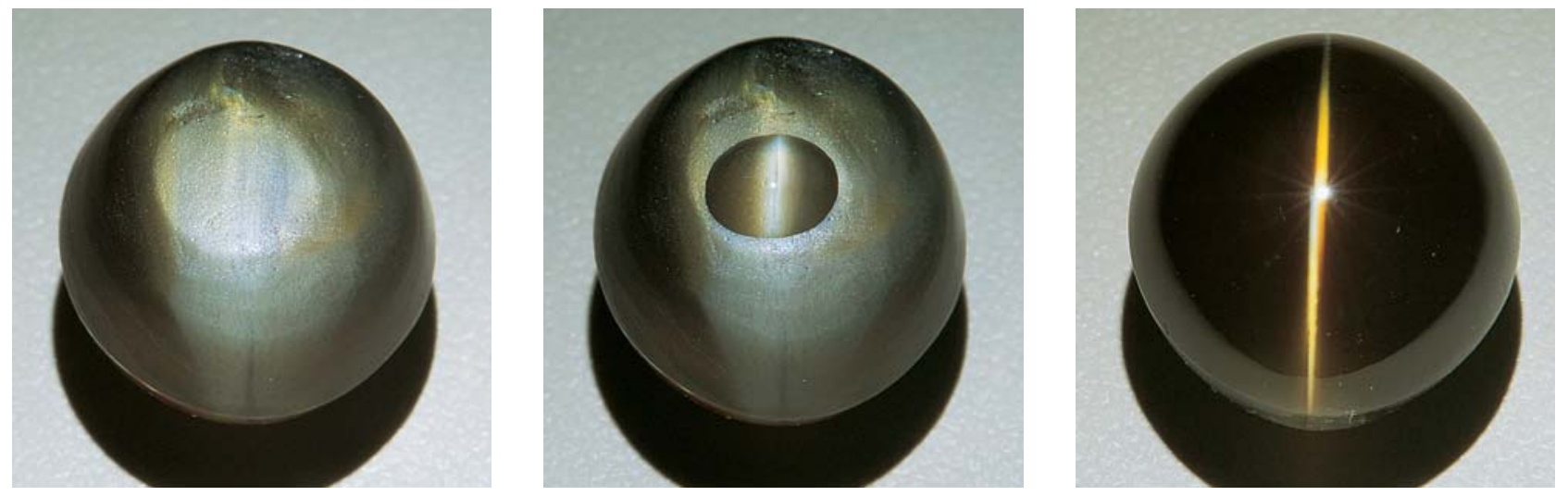
on top of the light source and then cover the upper portion with a finger while viewing the gem through its table with a standard loupe. By directing light obliquely through the pavilion, the gemologist will be better able to examine the interior of the gem (figure 8 inset). The loupe also should be used to confirm observations of surface characteristics previously made with the unaided eye.

A keen understanding of inclusions and other internal characteristics is essential when viewing the interior of a stone. Several inclusion reference books (see, e.g., Gübelin and Koivula, 1986; De Goutière, 1996; Shida, 1996, 1999; Koivula, 2000) should be reviewed when preparing for a buying trip. If you are looking for rubies and sapphires, for example, it may be prudent to color-photocopy the relevant sections from your favorite inclusion text to take along into the field. It is essential to practice identifying inclusions using a loupe. While still in the office or lab, after observing an inclusion scene with the microscope, practice viewing the same scene with a loupe. John Koivula, GIA's senior research gemologist, uses only his $10 \times$ loupe to locate the unusual inclusions he discovers every year at the Tucson shows.

Figure 8. It is the author's opinion that the darkfield loupe, with the standard flashlight attachment, is the single most significant development in portable gemological instruments for the serious gemologist. Inset: In the absence of a darkfield loupe, the effect may be approximated with an oblique illumination technique that simply requires placing the gem material in question on the glass of the light source and covering the exposed portion with a finger to create a shadow effect while simultaneously securing the gem in place. Photo by Maha Tannous; inset by Jason Stephenson.

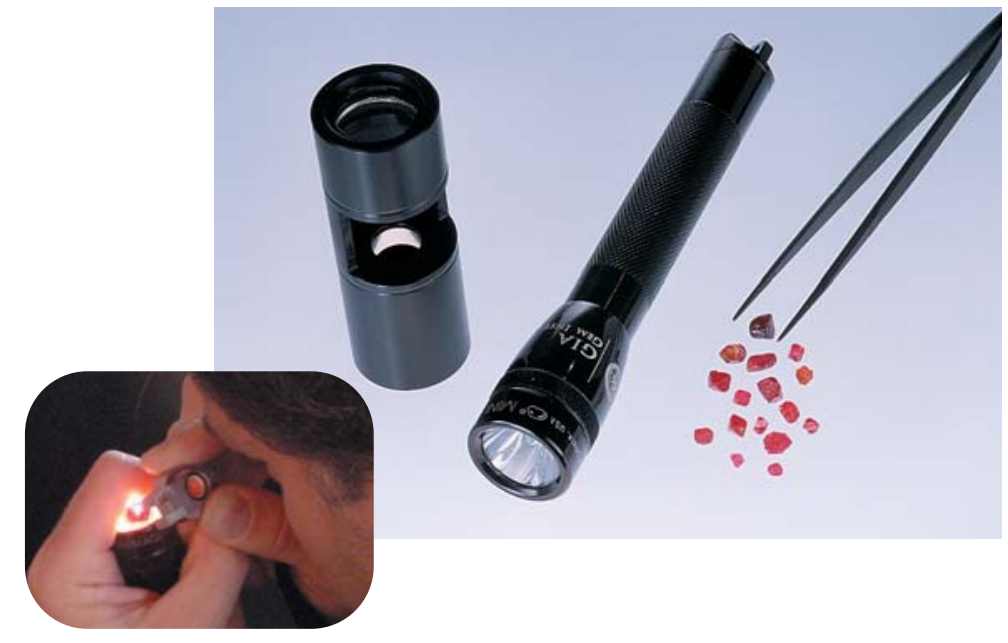


even the flash effect characteristic of fracture-filled diamonds may be easily seen with a darkfield loupe.

Likewise, the identification of many synthetics (e.g., curved striae or flux in some synthetic corundums, and metallic inclusions in some synthetic diamonds) can be made with a simple loupe. Also, the doubling of back facets in doubly refractive synthetic moissanite will easily separate this imitation from singly refractive diamond.

Lighting. Often overlooked, lighting conditions must always be observed and often manipulated to provide proper viewing of external and internal characteristics. Be aware of natural or extraneous lighting conditions. Various parts of the world have natural and artificial lighting that will make the gem look different there than at home. Natural lighting in northern hemispheres tends to favor the blue end of the spectrum, while natural lighting in southern hemispheres makes red, orange, and yellow stones look more attractive. Carrying a daylight-equivalent light source combined with a set of reference stones will minimize error. Many corundum dealers carry small samples of the colors they prefer.

Most third-world countries use fluorescent lighting that is either too blue or flickers due to inconsistent power supply. This can present disastrous results if one is not prepared. Trade shows, typically in large convention halls not designed for displaying gems, can be just as challenging. Again, being aware of the conditions and insisting on viewing a gem in

Figure 10. The gas bubbles in this glass imitation of aquamarine $(4.0 \times 4.0 \mathrm{~cm})$ are easily visible with the aid of $a 10 \times$ loupe and a powerful portable light source such as the Sure Fire light by Laser Products of Fountain Valley, California. Photo by Maha Tannous.

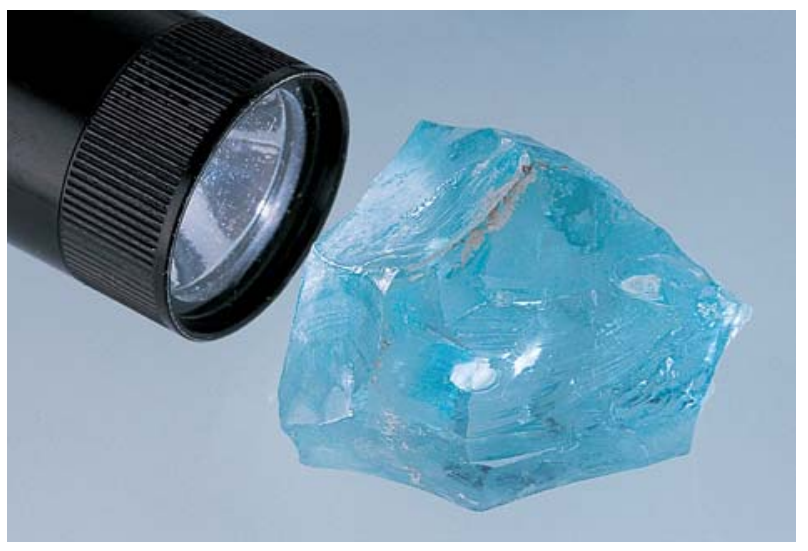

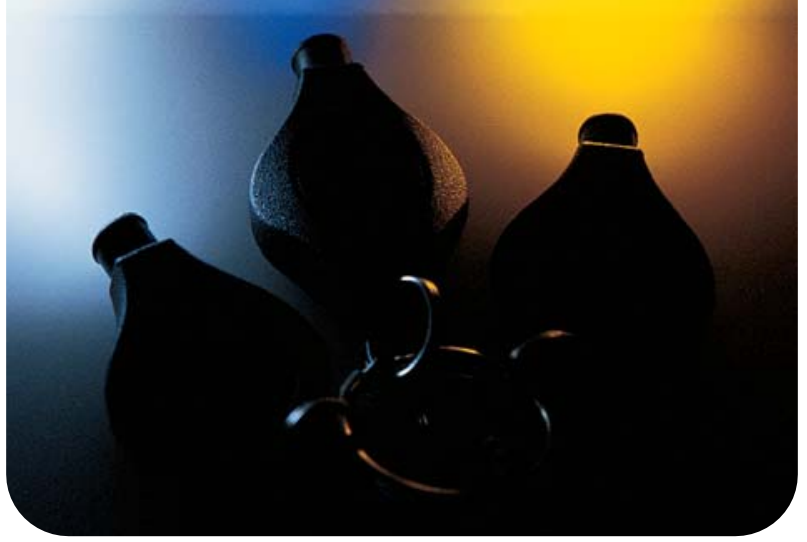

Figure 11. The most portable and lightweight lights currently available are manufactured by LRI Photon Micro-Lights, Blachly, Oregon. The output of each consists of (from left to right) $6500 \mathrm{~K}$ white light, $372 \mathrm{~nm}$ long-wave ultraviolet blue light, and 584-592 nm monochromatic yellow light. Photo by Maha Tannous.

daylight or controlled light may prevent a disappointing purchase.

Buyers of gem rough require much stronger portable lights than are needed for examining faceted gems. While the Sure Fire light (again, see figure 10) is one of the better flashlights available, even stronger illumination is sometimes needed for darker or larger rough. Welch Allyn, of Skan Falls, New York, produces a number of high-powered rechargeable lights with focus adjustments or fiberoptic attachments (initially developed for the medical industry) that are very useful for viewing rough gem materials.

Figure 12. The lipstick-size $(5.5 \times 1.5 \mathrm{~cm})$ long-wave portable ultraviolet lamp from Nebula, Redwood City, California, is one of the most durable UV lamps introduced in the last few years. Inset: Natural amber generally fluoresces blue under longwave UV fluorescence. Photos by Maha Tannous.

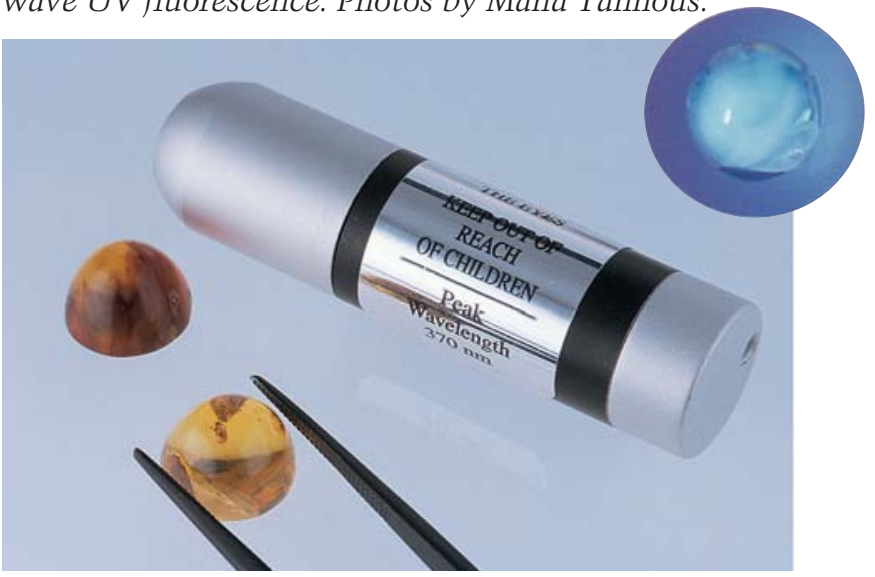


Among the most convenient new portable instruments are the Photon Micro-Lights, which are sold individually or as a set. The three most useful (figure 11) are the blue YAG phosphor diode lamp that provides long-wave UV radiation at $372 \mathrm{~nm}$, a yellow lamp at 584-592 nm, and a white-light lamp with an ideal daylight color temperature of approximately 6500 K (D. Allen, pers. comm., 2002). Each unit requires only two 3 -volt lithium coin cells, which makes them light and compact (with an active "life" of approximately 1,000 hours). The white light is useful to view gems such as alexandrite and diamond, which require daylight to make a proper assessment of quality and value. The monochromatic yellow light is the perfect compliment to a portable refractometer and even works well with the desktop version.

Fluorescence. In addition to the Photon Micro-Light blue YAG phosphor diode lamp noted above, a number of long-wave (approximately $370 \mathrm{~nm}$ ) ultraviolet lights are now available to gemologists (see, e.g., figure 12). A gem's response to UV radiation must be used only as an indicator, not as proof, but it can provide useful information. In locality determinations, for example, a fluorescent (chromium-rich, ironpoor) ruby may come from Myanmar or Vietnam, while a nonfluorescent (iron-rich) ruby may originate from Thailand or East Africa. Strong red fluorescence should always be cause for extra scrutiny, since almost all synthetic rubies exhibit this property. Amber generally fluoresces yellowish green (see figure 12 , inset), while plastic rarely does. Heat-treated sapphires often show orange fluorescence in zones previously occupied by rutile needles. Glass fillings in ruby can be detected when they fluoresce differently from their host. Many of the adhesives used to assemble crystals fluoresce green or yellow when exposed to long- or short-wave UV radiation.

Dichroscope. One gemological instrument that is portable, easy to use, and informative is the dichroscope (figure 13). If optic character is not readily apparent, the dichroscope should always be the second instrument used in the field. A dichroscope can readily distinguish between natural and imitation tanzanite or aquamarine (figure 14). This small, simple instrument often proves indispensable when judging tumbled rough that offers no clear view into its core. A dichroscope also helps the buyer determine the pleochroic colors that must be taken into consideration when the rough is to be fashioned.

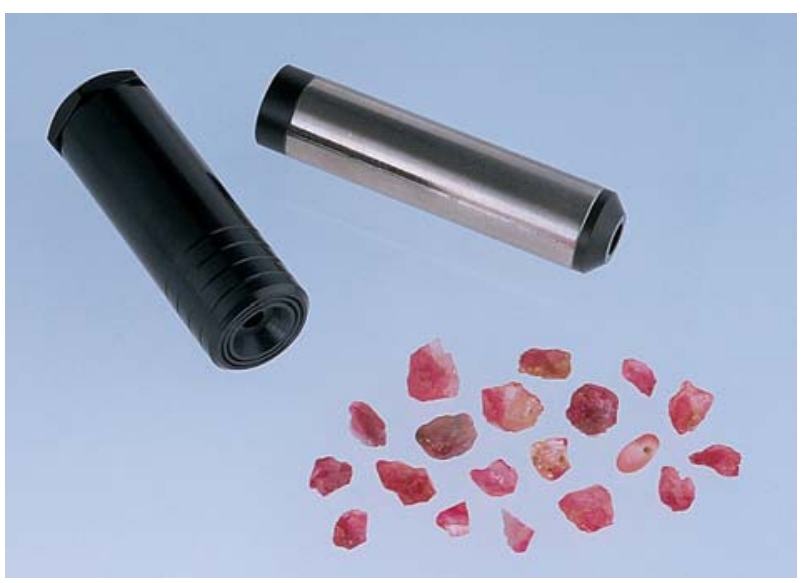

Figure 13. The OPL (Orwin Products, Ltd.) calcite dichroscope $(1$ eft, $4.0 \times 1.4 \mathrm{~cm})$ is one of the smallest dichroscopes on the market. It is most useful with faceted gems under $10 \mathrm{ct}$. The OPL diffraction grating spectroscope (right, $5.5 \times 1.3 \mathrm{~cm}$ ) is the smallest and most portable spectroscope on the market. Mastering this instrument takes practice, but it can be one of the most important tools for the traveling gemologist. Photo by Maha Tannous.

The directions of these colors relative to the shape of the rough are critical in the placement of the table, thereby dictating the yield and ultimate value of the finished gem.

The dichroscope made by Orwin Products Ltd., England (OPL) is excellent for viewing fashioned gems smaller than $10 \mathrm{ct}$. The new London Dichroscope, in the familiar "Chelsea" filter casing,

Figure 14. Natural aquamarine (left), glass imitation aquamarine (middle), and glass imitation tanzanite (right, $4 \times 3 \mathrm{~cm})$ are all easily separated by a dichroscope. Aquamarine, like tanzanite, will show the characteristic pleochroism of the natural gem, while the glass imitations will show no pleochroism. Photo by Maha Tannous.

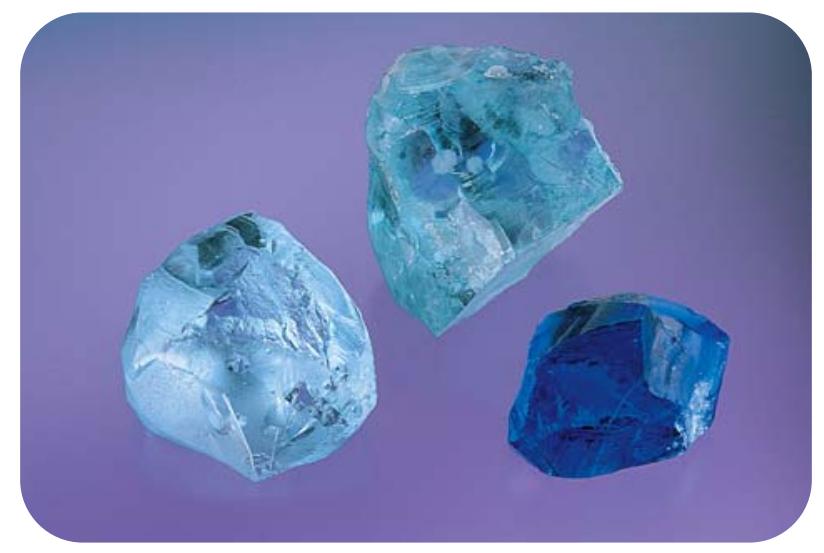




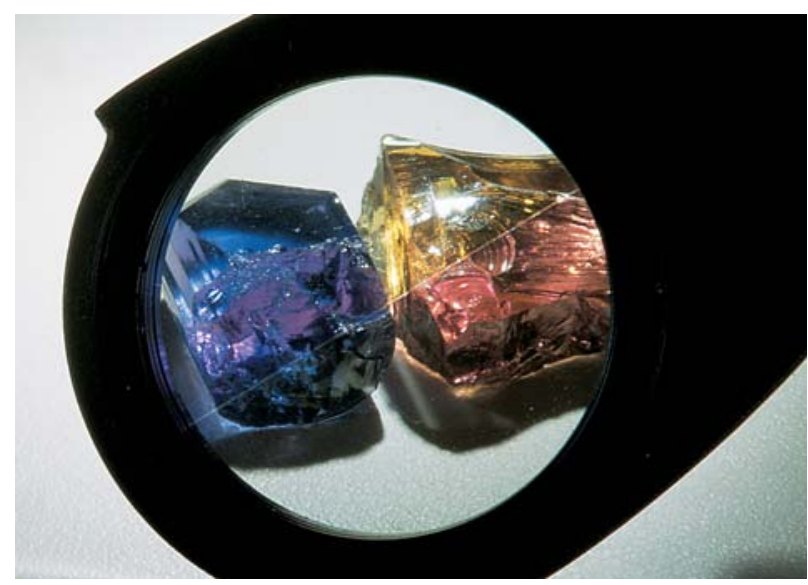

Figure 15. The new London Dichroscope, distributed by the Gemmological Association of Great Britain, has an expanded field of vision that makes it ideal for viewing larger gems or rough, such as this tanzanite (left, 2.57 grams) and pink zoisite (right, 2.9 grams). Stones courtesy of H. Krupp; photo by Maha Tannous.

uses crossed polarizers to provide a larger field of vision, making it more useful with rough and larger gems (figure 15). The Grieder dichroscope, available through Eichhorst Gem Instruments (Hamburg, Germany), uses the same technology to provide a similar field of vision. What is most important is to use the instrument that you are most familiar with and that gives you the best results.

Polariscope and Polarizing Filters. A polariscope attachment for a Mini Maglite or even just the lenses in a pair of polarized sunglasses can be used in place of a dichroscope or when more detailed information on optic character is needed (figure 16). For example, amethyst and scapolite have almost iden-

Figure 16. Attaching a polariscope to the end of a Mini Maglite provides an excellent portable tool for determining pleochroism and optic character. Photo by Maha Tannous.

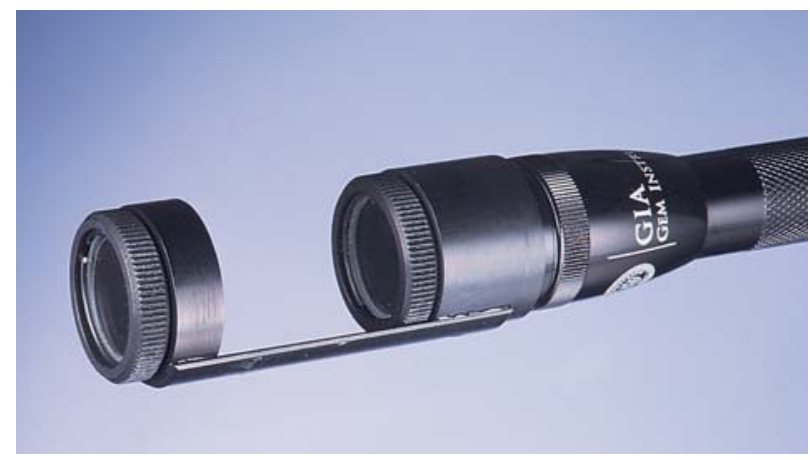

tical properties with the exception of their optic sign and scapolite's two directions of cleavage (typically evident only when viewing rough). Since amethyst is uniaxial positive $\left(\mathrm{U}_{+}\right)$and scapolite is uniaxial negative (U-), a polariscope combined with a condensing sphere and a magenta Polaroid filter may be used to differentiate them (figure 17).

Polarizing filters are useful for spotting the "tatami" or "tabby extinction" pattern in synthetic spinels, which are used to imitate many gems such as aquamarine (see, e.g., Gübelin and Koivula, 1986, p. 515). Such internal irregularities often may be seen only with crossed polarizers, and may also aid in judging the potential instability of highly strained rough as is often encountered in tourmaline and diamonds.

Spectroscope. Although the hand-held spectroscope is one of the most difficult portable gemological instruments to master, it also can be one of the most powerful in the field instrument arsenal. The prism and the diffraction-grating spectroscopes are the two types available. The diffractiongrating spectroscope (again, see figure 13) is smaller, more portable, and offers an even distribution of the visible color range, which makes it easier to see absorption lines in the red region. On the other

Figure 17. This illustration shows an optic axis figure as it would appear through a portable polariscope attachment using a glass condensing sphere and $a$ magenta Polaroid filter to distinguish between uniaxial positive $\left(U_{+}\right)$or uniaxial negative gems (U-). If the optic figure of the gem in question advances to $a$ blue color in the 1st and 3rd quadrants (parallel to the direction of the filter), as is the case with scapolite, then it is U-. A yellow color in the 1st and 3rd quadrants indicates a $U_{+}$gem such as quartz.

\section{UNIAXIAL OPTIC FIGURE}

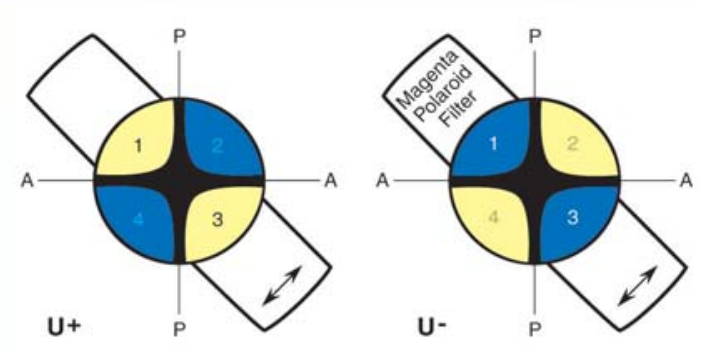




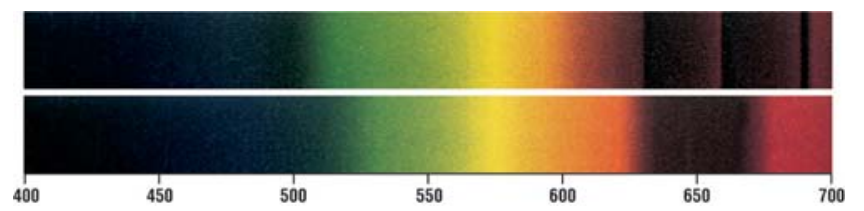

Figure 18. A spectroscope can readily separate natural-color jadeite (top) from typical dyed jadeite (bottom).

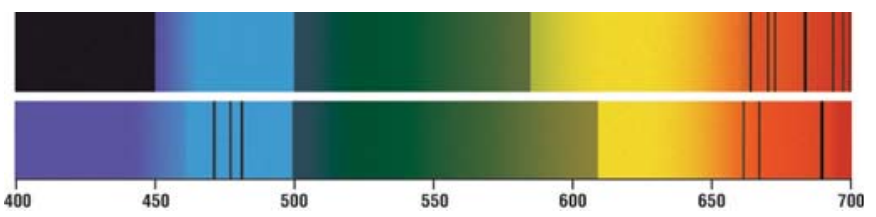

Figure 19. Also easily separated on the basis of their spectra are red spinel (top) and ruby (bottom). Spectra adapted with permission from Günther (1988).

hand, there are more published spectra available for the prism spectroscope. Again, take the instrument with which you have the most experience. It is very useful to take high-quality drawings or photos of spectra for reference in the field. In addition, a strong light source is essential to see the subtle spectral characteristics for most stones.

As with the loupe, a great deal of practice is required to master the spectroscope. And, as with inclusion scenes, key spectral patterns must be committed to memory before this instrument can provide its full potential. However, a knowledgeable gemologist can readily identify rough or polished zircon by virtue of its unique "organ pipe" pattern. Sometimes only one absorption line is needed to tell the buyer to beware of a dye, as with green jade (figure 18). Ruby and red spinel are easily distinguished by their characteristic spectra (figure 19).

Note, however, that some features may weaken or disappear when the gem is heated by the light source, as is the case with yellow diamonds that have been irradiated and annealed. (This also is true for some naturally occurring spectral features, such as "Cape lines.") Therefore, it is important to recognize the telltale characteristics as quickly as possible (see, e.g., Günther, 1988; Anderson, 1990). Placing a yellow diamond on a cube of ice will delay the warming effect of the incandescent light.

Refractometer. Although a portable refractometer can be indispensable in certain situations, carrying
R.I. fluid and finding the time and a place to use this instrument can pose problems in a field setting. There are a few miniature refractometers on the market (such as the GIA Gem Instruments Duplex III pocket refractometer and the Gemological Products GemPro portable refractometer), and some fortunate gemologists still own the early-model GIA Gem Instruments refractometer designed by Robert Shipley Jr. and introduced in 1949 (figure 20; Shipley Jr. and Alton, 1949). Again, it is important to practice using this instrument and to note the subtle differences when monochromatic light is not available (Mappin, 1945). The perfect compliment to a field refractometer is the new yellow Photon Micro-Light shown in figure 11.

Figure 20. Among the portable refractometers currently available is the GIA Gem Instruments Duplex III (shown with a $4.95 \mathrm{ct}$ spinel). The inset shows the GIA Gem Instruments refractometer designed by Robert Shipley Ir. that was introduced in 1949. At 5.2 $\times 4.8 \mathrm{~cm}$, it is still considered one of the most durable and portable refractometers ever made (E. Gübelin, pers. comm., 2002). Photos by Maha Tannous.

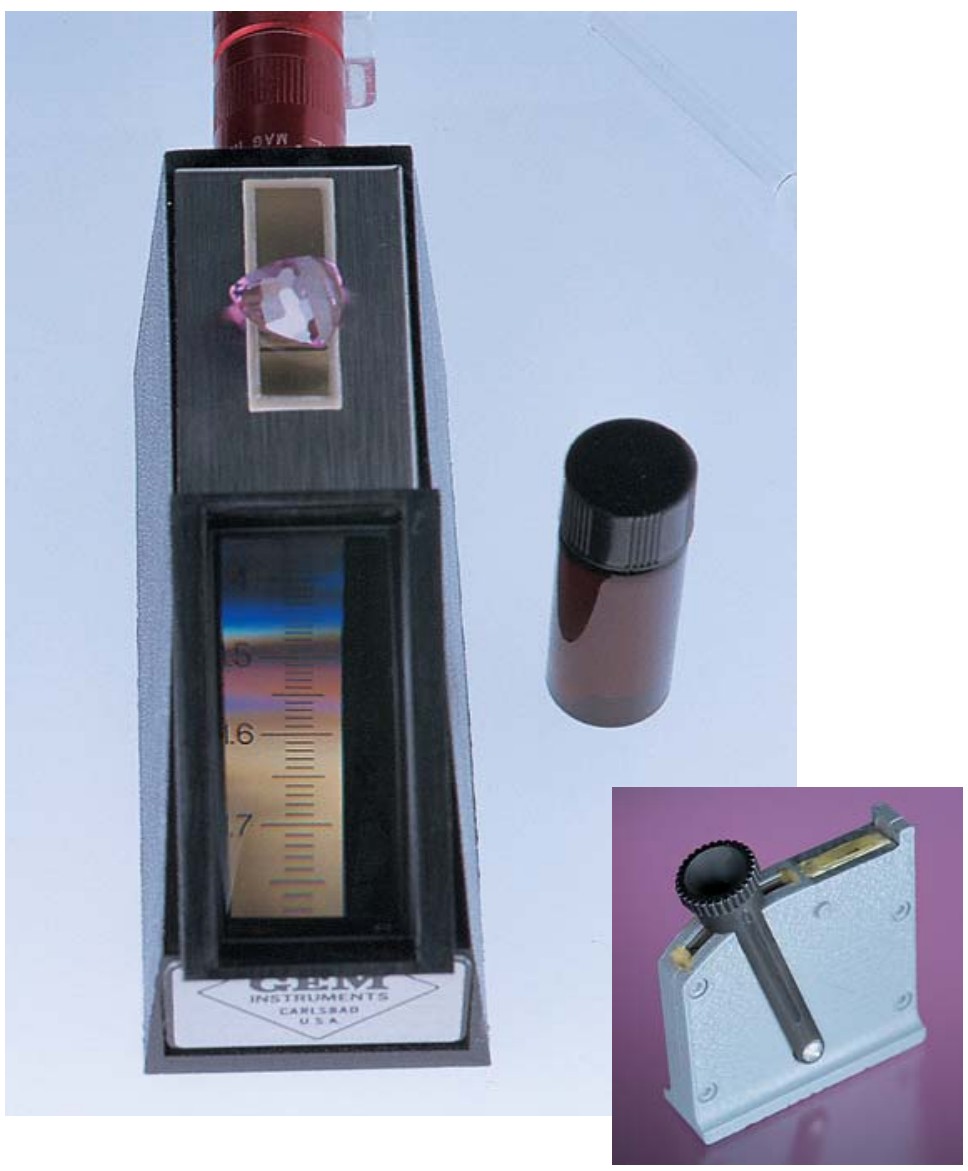




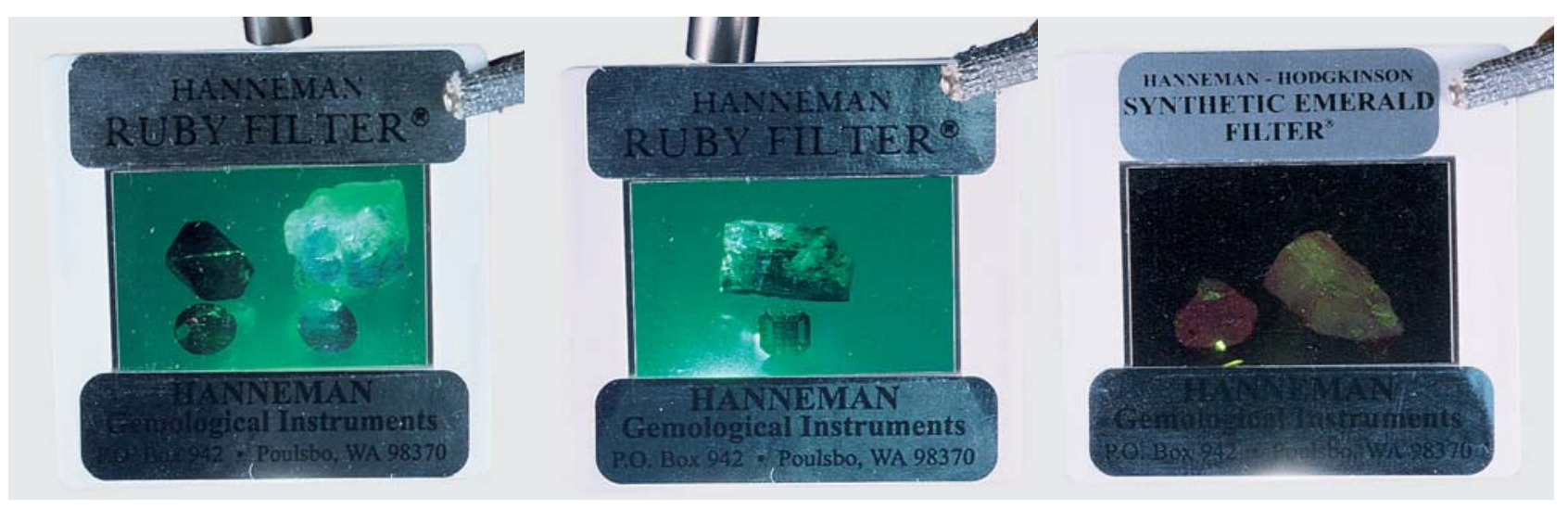

Figure 21. In the photo on the left, a faceted red spinel and a red spinel crystal both appear dark gray through the Hanneman Ruby Filter, whereas a faceted ruby and a ruby crystal on calcite matrix both appear blue through the same filter. In the center photo, a large red beryl crystal and faceted red beryl both appear grayish through the Hanneman Ruby Filter. On the far right, a faceted green YAG and a Chatham synthetic emerald crystal both appear pink when viewed through a Hanneman-Hodgkinson Synthetic Emerald filter. Photos by Maha Tannous.

Filters and the Hodgkinson "Visual Optics" Method. The versatile Chelsea filter (again, see figure 5) and the numerous filters invented by Dr. W. Hanneman and Alan Hodgkinson are among the many filters that are valuable when used properly.

Some filters target specific gems (e.g., ruby, tanzanite, and aquamarine). The Hanneman Ruby Filter is quite useful in distinguishing between ruby

Figure 22. The narrow white flares from a faceted diamond (left) readily separate it from the broad spectral

flashes of a faceted synthetic moissanite (right) illustrating the differences in dispersion - when the two round brilliants are submerged in water and illuminated from above through a pinhole with a

focused light source. This concept of optical dispersion is the essence of the Hodgkinson "Visual Optics" method. Photo by Alan Hodgkinson.

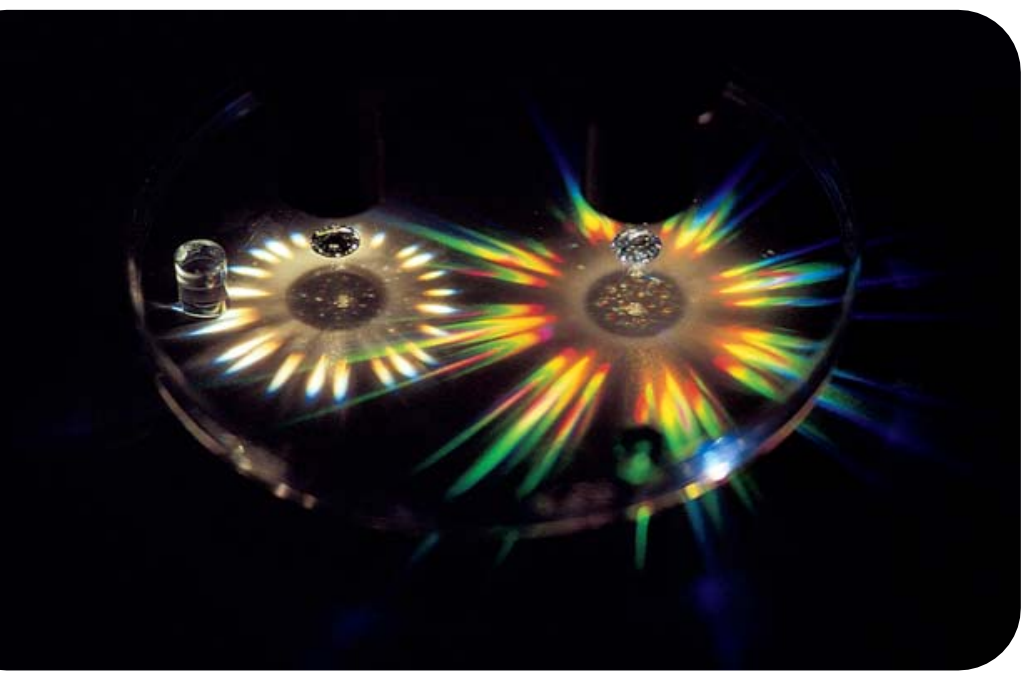

and other red gems (figure 21, left and center). The Synthetic Emerald Filter, invented by Alan Hodgkinson, can separate a synthetic from a natural emerald even through a glass window or showcase (Hodgkinson, 1995a). If the total body color of the emerald appears pink through the filter, then it could be a synthetic emerald or perhaps a YAG (A. Hodgkinson, pers. comm., 2002; figure 21, right). In contrast, natural emerald appears greenish or loses its body color. Dr. Hanneman recently developed a filter for distinguishing tanzanite from its two most common imitations, glass and synthetic forsterite (Hodgkinson, 2001).

It is important to recognize that filters can assist in the identification process, but they are not to be used for definitive determinations. Nonetheless, they are valuable aids to identification and can save time. In practiced hands, these filters allow for instantaneous, inexpensive screening of entire parcels.

Hodgkinson (1995b) also has developed an overall optical system of gem identification, which he named "Visual Optics." By holding the table facet of a gem (loose or mounted) close to the eye and looking at a distant bright light source, the gemologist can observe and estimate refraction, dispersion, and birefringence. In some cases-as with ruby, diamond, darker tourmalines, and lead glass-recognition may be instantaneous. Any gemologist who has taken the time to train his or her eye to this method may also quickly eliminate other possibilities.

A pinhole instrument has been developed that, used in conjunction with standard focused illumination, permits side-by-side demonstration of the Hodgkinson method (A. Hodgkinson, pers. comm., 2002). This instrument is especially useful to sepa- 


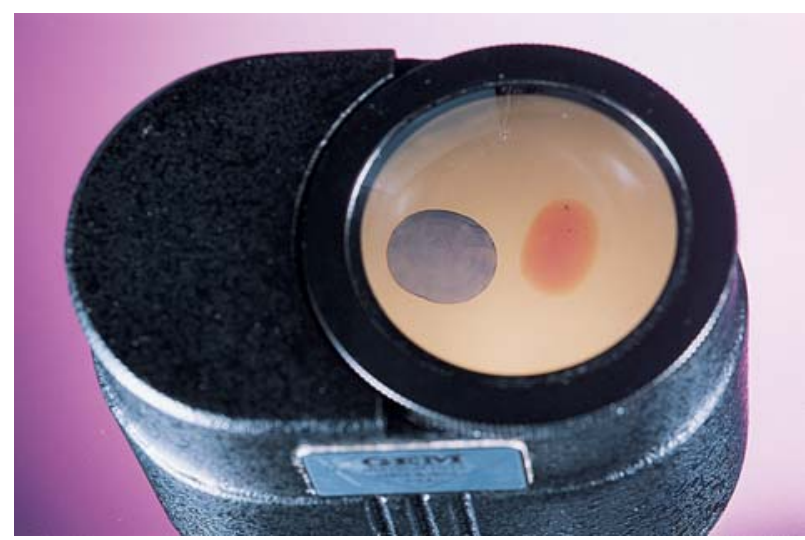

Figure 23. Diffusion detectors can be very useful for detecting surface-diffused gems, even when water or oil is used as the immersion medium rather than methylene iodide. Surface-diffused sapphires (here, a blue sapphire on the left showing blue color concentrations along the facet junctions, next to an orangy pink sapphire with a distinctive rim of surface color) continue to pose identification challenges for gemologists. Photo by Maha Tannous.

rate diamond from its closest imitation, synthetic moissanite (figure 22). The synthetic moissanite disperses light into broad spectral flashes, whereas the diamond disperses narrower white flashes (A. Hodgkinson, pers. comm., 2002). It is essential to notice the relative angle and spread of the spectral colors as light passes through the sample. In essence, since light travels slower in highly refractive gems such as a diamond or cubic zirconia, the spectral clusters will be more spread out. In contrast, gems with lower refractive indices, such as quartz or peridot, will not spread light as much and thus will exhibit a tighter grouping of spectral clusters. This test is only useful for faceted gems and requires considerable practice, but it can provide a quick clue to a stone's refractive properties.

Diffusion Detectors. Several practical containers"immersion cells" - that are useful for viewing potential diffusion-treated sapphires or rubies were introduced a number of years ago. The stone is placed in the upper compartment containing a liquid to reduce reflection. Methylene iodide (diiodomethane) is most useful because its refractive index of 1.74 is so close to that of corundum and other gem materials. However, even water (R.I.=1.33) or olive oil (R.I.=1.47), which are less toxic and easier to come by in the field, may be used. These diffusion detectors can reveal concentrations of color along pavilion facet junctions (in the case of blue diffusion-treated sapphires) or surface layers of color (in the case of the new orangy pink to orange treated sapphires), as illustrated in figure 23 . Immersion also may help expose curved striae in flame-fusion synthetic rubies that have been tumbled to resemble waterworn rough crystals (Koivula et al., 1992). Such rough corundum imitations are sometimes offered at the source to either deceive or test the buyer. Usually, if a buyer can show gemological expertise, fewer and fewer synthetics and imitations will be included in the goods offered.

Two well-known immersion instruments are the GIA Gem Instruments diffusion detector with a self-contained light source (again, see figure 23) and the ROS/Gem Optics diffusion detector with the smallest of the Maglites, the Solitaire. The latter is somewhat more portable because of the external light source.

The Last Resort: Hardness Testers. Hardness may be detected visually by rounding of facet junctions and scratches on stones, as described earlier, and provides helpful clues in narrowing the field of possibilities. As a last resort, when judging rough, a portable hardness kit can also be quite useful (figure 24). Local crystals of known hardness may be just as effective as a hardness kit. Faceted gems should never be subjected to scratch testing; there are so many other (nonde-

Figure 24. As a last resort, a portable hardness testing kit (here, $6.5 \times 4.0 \mathrm{~cm}$ ) can aid in identifying rough when visual testing is reduced due to a rough surface or natural tumbling. Hardness testing should not be done on fashioned gems. Photo by Maha Tannous.

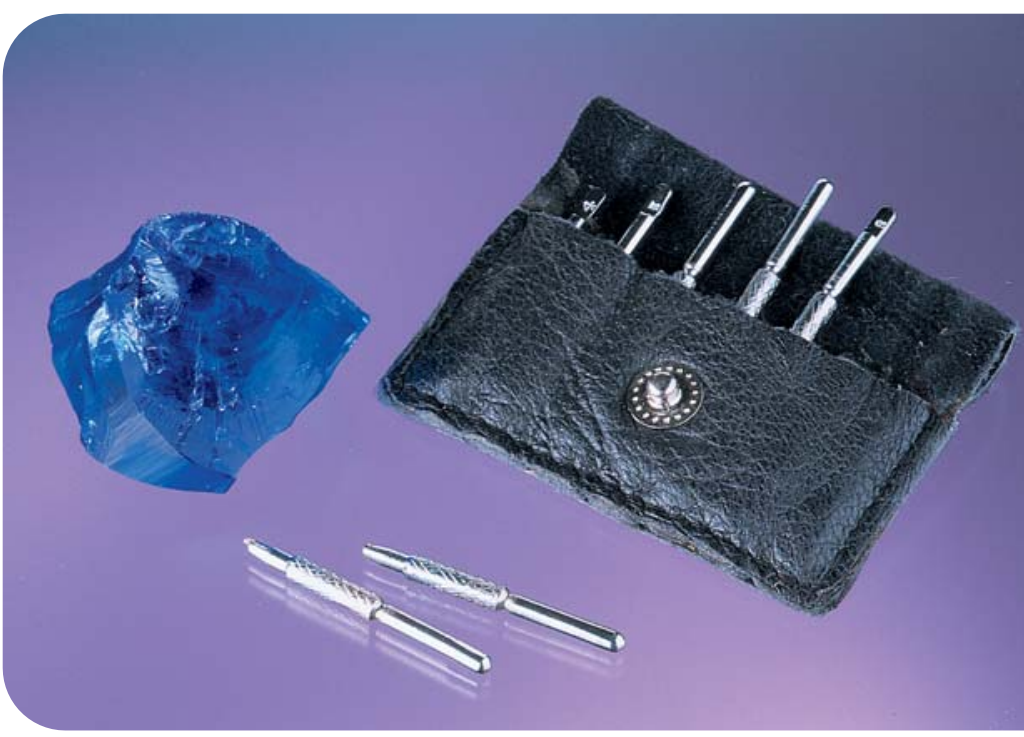


structive) ways to identify them. As with heft, judging the relative hardness of a gem requires practice at home that could be applied in the field.

Recent Additions. Among the newest instruments to enter the field arsenal is the SSEF Diamond Spotter (figure 25)-which is a useful first step in identifying HPHT-treated diamonds. This practical instrument, developed by the SSEF Swiss Gemmological Institute in Basel, Switzerland, in collaboration with Dr. Emmanuel Fritsch at the University of Nantes in France, may be used to distinguish type IIa (those that may undergo or have already undergone HPHT treatment) and type IIb diamonds, both of which transmit short-wave ultraviolet radiation, from their more common type I counterparts (J-P. Chalain, pers. comm., 2002). The diamond is secured with BluTack over the opening on the cylinder and then exposed to short-wave UV. If the diamond transmits short-wave $\mathrm{UV}$, then the UV-sensitive area will fluoresce green. If the diamond absorbs short-wave UV, then the UVsensitive area will remain white. Ideally, the diamond should be positioned so the incident UV light is perpendicular to the crown, pavilion, or girdle, allowing the light to travel directly through the stone with minimal reflection.

Although extremely rare, type IaB diamonds also transmit short-wave UV; however, thus far no HPHT treatment has been described in the gemological literature as being applied to natural type IaB

Figure 25. The SSEF Diamond Spotter (left, $4.0 \times 2.8$ $\mathrm{cm}$ diameter) is one of the newer instruments invented to help gemologists deal with some of the latest identification challenges. Even with the table down, the green fluorescence visible on the screen below the $1.08 \mathrm{ct}$ diamond on the SSEF Diamond Spotter (right) indicates that the diamond is type IIa or IIb. Photos by Maha Tannous.

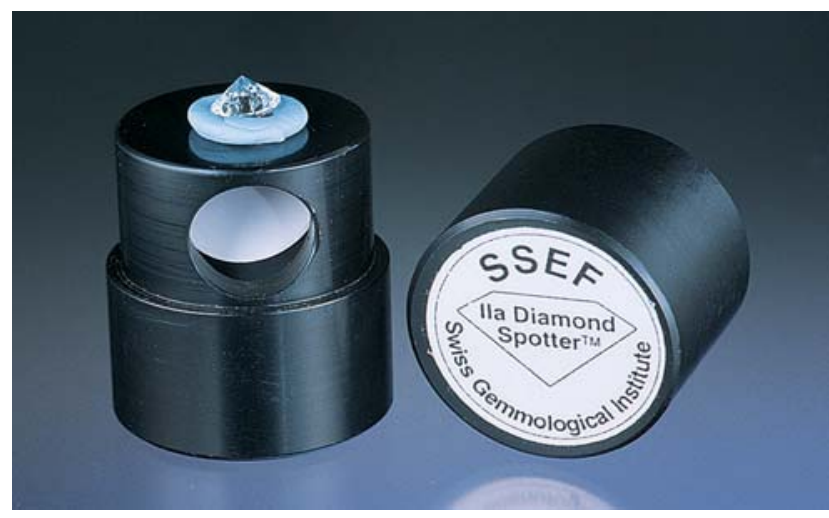

diamonds. This instrument also may be used to separate natural colorless corundum, which absorbs short-wave UV, from Verneuil synthetic corundum, which transmits short-wave UV. Cubic zirconia and synthetic moissanite both absorb short-wave UV (Hänni and Chalain, 2002).

Important References. While suitable portable instruments are essential, a reference manual also may save time and money. There are numerous books that can assist in honing your field gemology skills, such as Liddicoat (1989), Anderson (1990), Hurlbut and Kammerling (1991), Webster (1994), GIA's Gem Reference Guide (1995), and (the most compact) Schumann (1997).

The single most important reference items are gemological property charts, such as the " $\mathrm{A}$ " and "B" charts published by GIA. High-quality drawings of gem spectra and inclusions also are very useful.

\section{CONCLUSION}

The use of portable instruments and field methods requires time and patience to master. Yet some of the most significant developments in gemology, such as the darkfield loupe, have occurred while trying out new testing techniques when standard lab equipment was not available. As with all identifications, it is essential to follow four basic steps, in the following order:

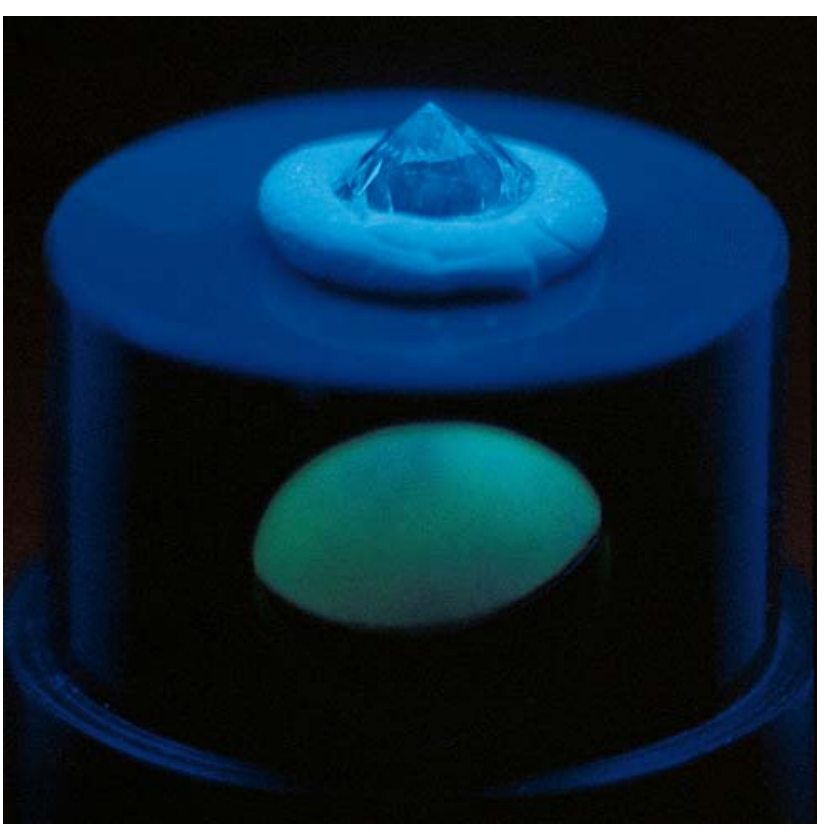


1. Search for obvious surface clues.

2. Loupe the stone for internal characteristics.

3. Determine the material's general optic character.

4. Gather additional information with a handheld spectroscope, polariscope, ultraviolet lamp, refractometer, and the like, to further narrow down the possibilities.

A portable laboratory, such as the MaxiLab or PortaLab (figure 26), can be indispensable when making purchases in the field or at trade shows. However, it usually is not practical to carry an entire kit on every buying trip. Thus, skill in using pocket-sized portable instruments is essential. Practicing the use of these portable instruments long before you plan a gem-buying trip will greatly heighten the skills and senses needed to make the quick decisions in the field that could save you time and money.

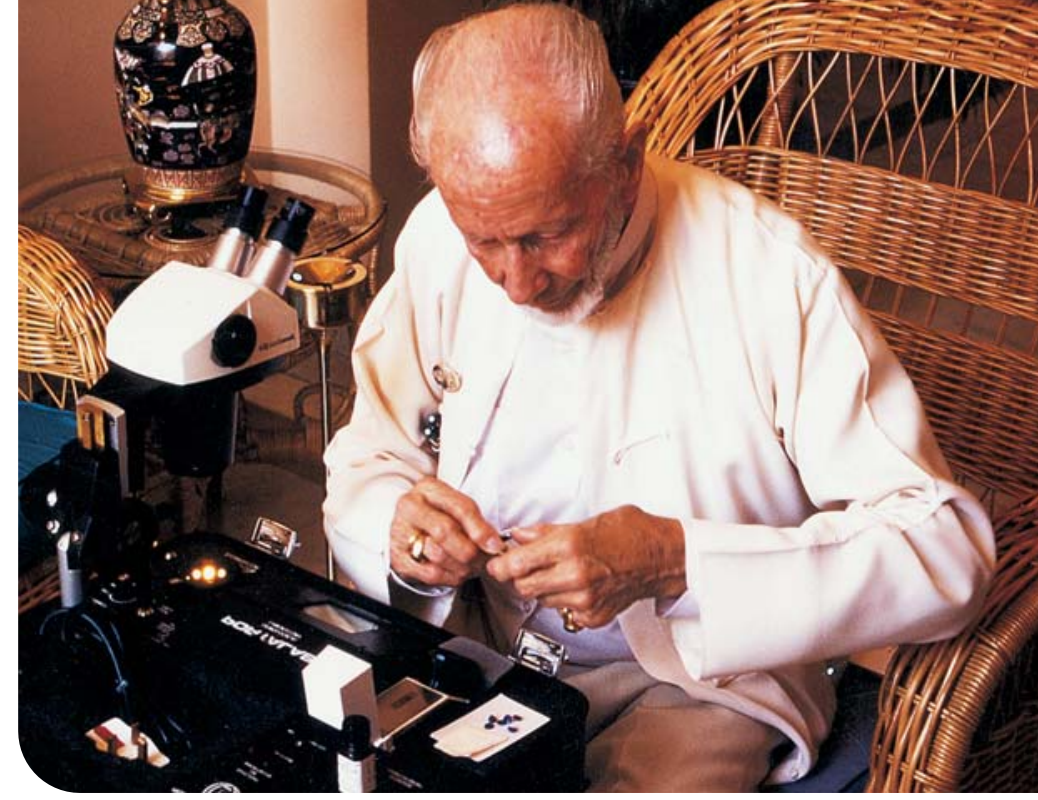

\section{ABOUT THE AUTHOR}

Edward Boehm (joebgem@aol.com) is president of JOEB Enterprises in Solana Beach, California, a firm that specializes in loose colored stones and museum consulting. Acknowledgments: The author thanks Richard $T$. Liddicoat for his enduring inspiration and for the numerous updates he has published on new developments in gemological instrumentation over the years. Also, thanks go to Jo-Ellen Cole of Jo-Ellen Cole Appraisal Services, Carlsbad, for her assistance with the initial editing and to

Figure 26. Prominent gemologist Dr. Edward Gübelin is shown here using a Portalab inYangon, Myanmar (Rangoon, Burma) at the 30th Myanma Gems, Jade, « Pearl Emporium in 1993. Photo by Edward W. Boehm.

Jason Stephenson of Hubert Gems in Los Angeles, for his help with the initial digital photography. Alan Hodgkinson (Ayrshire, Scotland) and David Allen (LRI, Blackly, Oregon) are thanked for providing information on their instruments. Many thanks to Maha Tannous for her hours of photographic expertise and to the reviewers for their constructive comments, support, and assistance.

Finally, special thanks to Dr. E. Gübelin for his generous tutelage on field and lab identification, and for his pioneering influence on the development of gemological testing equipment.

\section{REFERENCES}

Anderson B.W. (1990) Gem Testing, 10th ed. Rev. by E. A. Jobbins, Butterworths, London, 390 pp.

De Goutière A. (1996) Wonders within Gemstones. Gemworld International, Northbrook, IL, 1996, 135 pp.

Gem Reference Guide (1995) Gemological Institute of America, Santa Monica, CA, 1995, 270 pp.

Gübelin E., Koivula J. (1986) Photoatlas of Gemstone Inclusions. ABC Edition, Zurich, Switzerland, $532 \mathrm{pp}$.

Günther B. (1988) Tables of Gemstone Identification. Verlagsbuchhandlung Elisabeth Lenzen, Kirschweiler, 162 pp. [In German and English, with 45 pp. supplement.]

Hanneman W.W. (2001) Dispersion, birefringence and the critical angle refractometer. Australian Gemmologist, Vol. 21, No. 22, pp. 88-91.

Hänni H., Chalain J-P. (2002) SSEF Diamond Spotter and SSEF Diamond Illuminator from SSEF Swiss Gemmological Institute. Instruction sheet, version 2, SSEF, Basel, Switzerland, 2 pp.

Hodgkinson A.H. (1995a) The Hanneman-Hodgkinson Synthetic Emerald Filter. Canadian Gemmologist, Vol. 16, No. 1, pp. 18-22.

Hodgkinson A.H. (1995b) Visual Optics, The Hodgkinson Method. Gemworld International, Northbrook, IL, 50 pp.

Hodgkinson A. (2001) Scottish gem lab news, tanzanites and others. Australian Gemmologist, Vol. 21, No. 2, pp. 83-87.

Hurlbut C.S. Jr., Kammerling R.C. (1991) Gemology, 2nd ed. John Wiley \& Sons, New York.

Koivula J.I. (2000) The Microworld of Diamonds. Gemworld International, Northbrook, IL, $157 \mathrm{pp}$.
Koivula J.I., Kammerling R.C., Fritsch E.F., Eds. (1992) Gem News: More synthetics sold as natural rubies in Vietnam. Gems \&) Gemology, Vol. 28, No. 2, p. 139.

Liddicoat R.T. (1981) A brief summary of gemmological instrument evolution. Journal of Gemmology, Vol. 27, No. 8, pp. 568-583.

Liddicoat R.T. (1982) A brief summary of gem testing instrument evolution. In D.M. Eash, Ed., Proceedings of the International Gemological Symposium, 1982, Gemological Institute of America, Santa Monica, CA, pp. 15-21.

Liddicoat R.T. (1989) Handbook of Gem Identification, 12th ed. Gemological Institute of America, Santa Monica, CA, 440 pp.

Mappin K.G. (1945) Use of the refractometer. Gems «) Gemology, Vol. 5, No. 3, pp. 247-250.

Matlins A.L., Bonanno A.C. (1997) Gem Identification Made Easy: A Hands-On Guide to More Confident Buying and Selling. Gemstone Press, Woodstock, VT, 322 pp.

Schumann W. (1997) Gemstones of the World, 2nd ed. Sterling Publishing Co., New York, 271 pp.

Shida J. (1996) The Science of Gemstone Nebula, Vol. 1. Eiichi Tsuruoka Publishing, GAAJ, Tokyo, Japan, 366 pp.

Shida J. (1999) The Science of Gemstone Nebula, Vol. 2. Eiichi Tsuruoka Publishing, GAAJ, Tokyo, Japan, 520 pp.

Shipley R.M. Jr., Alton N.S. (1949) A new technique for gemstone identification. Gems «) Gemology, Vol. 6, No. 5, pp. 136-143.

Sinkankas J. (1955) Gem Cutting: A Lapidary's Manual. D. Van Nostrand Co., Princeton, NJ, 413 pp.

Webster R. (1994) Gems: Their Sources, Descriptions and Identification, 5th ed. Revised by P.G. Read, Butterworth Heinemann, London. 